\title{
OPERATOR FUNCTIONS IMPLYING GENERALIZED FURUTA INEQUALITY*
}

\author{
TAKAYUKI FURUTA, TAKEAKI YAMAZAKI AND MASAHIRO YANAGIDA
}

Abstract. As further extensions of the main result in [11], we show the following result.

Let $A \geqslant B \geqslant 0$ with $A>0$. For each $t \in[0,1]$ and $p \geqslant t$, the following (i) and (ii) hold for a fixed real number $q$ and they are mutually equivalent:

(i) if $q \geqslant 0$, then

$$
G_{p, q, t}(A, B, r, s)=A^{\frac{-r}{2}}\left\{A^{\frac{r}{2}}\left(A^{\frac{-t}{2}} B^{p} A^{\frac{-t}{2}}\right)^{s} A^{\frac{r}{2}}\right\}^{\frac{q-t+r}{(p-t) s+r}} A^{\frac{-r}{2}}
$$

is decreasing for $r \geqslant t$ and $s \geqslant 1$ such that $(p-t) s \geqslant q-t$.

(ii) if $p \geqslant q$, then

$$
G_{p, q, t}(A, B, r, s)=A^{\frac{-r}{2}}\left\{A^{\frac{r}{2}}\left(A^{\frac{-t}{2}} B^{p} A^{\frac{-t}{2}}\right)^{s} A^{\frac{r}{2}}\right\}^{\frac{q-t+r}{(p-t) s+r}} A^{\frac{-r}{2}}
$$

is decreasing for $s \geqslant 1$ and $r \geqslant \max \{t, t-q\}$.

Mathematics subject classification (1991): 47A63.

Key words and phrases: Löwner-Heinz inequality, Furuta inequality, chaotic order.

\section{REFERENCES}

[1] T. ANDo, On some operator inequalities, Math. Ann. 279 (1987), 157-159.

[2] T. ANDO AND F. HIAI, Log-majorization and complementary Golden-Thompson type inequalities, Linear Algebra Appl. 197, 198 (1994), 113-131.

[3] M. FuJII, Furuta's inequality and its mean theoretic approach, J. Operator Theory 23 (1990), 67-72.

[4] M. FUJII, T. FURUTA AND E. KAMEI, Furuta's inequality and its application to Ando's theorem, Linear Algebra Appl. 179 (1993), 161-169.

[5] M. FuJII AND E. KAMEI, Mean theoretic approach to the grand Furuta inequality, Proc. Amer. Math. Soc. 124 (1996), 2751-2756.

[6] T. FURUTA, $A \geqslant B \geqslant 0$ assures $\left(B^{r} A^{p} B^{r}\right)^{1 / q} \geqslant B^{(p+2 r) / q}$ for $r \geqslant 0, p \geqslant 0, q \geqslant 1$ with $(1+2 r) q \geqslant p+2 r$, Proc. Amer. Math. Soc. 101 (1987), 85-88.

[7] T. FURUTA, Elementary proof of an order preserving inequality, Proc. Japan Acad. 65 (1989), 126.

[8] T. FuRUTA, Two operator functions with monotone property, Proc. Amer. Math. Soc. 111 (1991), 511-516.

[9] T. FURUTA, Applications of order preserving operator inequalities, Operator Theory: Advances and Applications 59 (1992), 180-190.

[10] T. FuRUTA, Extension of the Furuta inequality and Ando-Hiai log-majorization, Linear Algebra Appl. 219 (1995), 139-155.

[11] T. FURUTA AND D. WANG, A decreasing operator function associated with the Furuta inequality, preprint.

[12] E. KAMEI, A satellite to Furuta's inequality, Math. Japon. 33 (1988), 883-886.

[13] K. TAnahashi, Best possibility of the Furuta inequality, Proc. Amer. Math. Soc. 124 (1996), 141-146. 